\title{
Profile of ciclesonide for the maintenance treatment of asthma
}

This article was published in the following Dove Press journal:

Therapeutics and Clinical Risk Management

18 August 2011

Number of times this article has been viewed

\section{Effie Singas ${ }^{1,2}$ \\ Jill P Karpel ${ }^{3,4}$}

'North Shore University Hospital, NS-LIJ Health System, ${ }^{2}$ Hofstra North Shore - LIJ School of Medicine, ${ }^{3}$ North Shore Medical Arts, ${ }^{4}$ Albert Einstein College of Medicine, New York, NY, USA
Correspondence: Effie Singas

4I0 Lakeville Road, Suite 107,

New Hyde Park, NY I I040, USA

$\mathrm{Tel}+\mathrm{I} 5164655400$

Fax +I 5164655454

Email esingas@nshs.edu
Abstract: Ciclesonide is a nonhalogenated synthetic inhaled corticosteroid (ICS) that has been approved by the US Food and Drug Administration for the treatment of all severities of persistent asthma. It is available as a hydrofluroalkane pressurized metered-dose inhaler in two strengths, $80 \mathrm{mcg} /$ activation and $160 \mathrm{mcg} /$ activation, with the recommenced dosage being two inhalations twice-daily. It is a prodrug that is converted in the lung to its active form, which possesses 100-fold greater glucocorticoid-receptor-binding affinity than the parent compound. Its relative receptor affinity is similar to budesonide. In clinical studies, ciclesonide was effective in improving pulmonary function, reducing asthma symptoms, and reducing or eliminating the need for oral corticosteroids (OCSs). Patients with severe asthma dependent on OCSs and high doses of ICSs were able to achieve greater asthma control and reduce or even eliminate the use of OCSs when switched to ciclesonide. In comparison with fluticasone propionate and budesonide, ciclesonide was demonstrated to be at least as effective in maintaining pulmonary function and asthma control. In clinical trials, ciclesonide was well tolerated, with the majority of adverse events considered mild or moderate in intensity. It had low systemic bioavailability and no clinically significant hypothalamic-pituitary-adrenal axis suppression at therapeutic doses. Its safety profile establishes ciclesonide as an important addition to the currently available ICSs.

Keywords: ciclesonide, asthma, maintenance, corticosteroids

\section{Introduction}

Asthma is a chronic inflammatory disease of the airways that results in airway obstruction that is thought to be largely reversible. It is characterized by recurrent episodes of wheezing, dyspnea, chest tightness, and coughing. There is a significant health burden associated with asthma due to its resultant morbidity, mortality, and cost.

Both national and international guidelines have been developed to improve the diagnosis, management, and outcomes of asthma. ${ }^{1,2}$ For all categories of persistent asthma, inhaled corticosteroids (ICSs) are the cornerstone or first-line therapy due to their potent anti-inflammatory properties, which primarily result in reduced numbers of airway inflammatory cells and their subsequent mediators. Clinically, they reduce bronchial hyperreactivity, asthma symptoms, exacerbations, urgent care visits, and hospitalizations, while improving lung function and quality of life.

Current guideline recommendations are to treat mild asthma with a low-dose ICS, while moderate asthma (patients $\geq 12$ years) may be treated with either a medium-dose ICS or a low-dose ICS with the addition of a long-acting-beta-2-agonist (LABA). ${ }^{1}$ For severe persistent asthma patients, combination therapy with a medium- to high-dose ICS plus a LABA is recommended, possibly with the addition of omalizumab or oral 
corticosteroids (OCS) if control is not achieved. However, it is also a guideline recommendation that once control is achieved for a period of time (ie, at least 3 months), the ICS dose should be titrated downward to the lowest dose possible to maintain control. This is to hopefully minimize any systemic absorption that might result in potentially adverse effects such as hypothalamic-pituitary-adrenal axis (HPA axis) suppression, growth retardation in children, decreased bone mineral density, cataracts, skin thinning, and easy bruising. ICSs are usually well tolerated and considered to be safe at the recommended doses. The occurrences of adverse effects are considered to be related to both the dose administered and the duration of treatment. When treating patients with asthma, the risk/benefit of each treatment step (up or down) should be weighed against the outcomes associated with uncontrolled asthma.

In keeping with the above philosophy, newer ICSs are being developed to address the needs unmet by current ICS therapy. Some of the goals in the development of new ICSs would be to: improve therapeutic indexes, particularly at higher dosages; have less frequent dosing intervals to encourage patient adherence; and maintain clinical effectiveness and potency.

Ciclesonide (CIC) is indicated for the treatment of persistent asthma in patients aged 12 years or older. It is available in a hydrofluroalkane pressurized metered-dose inhaler (HFA-MDI) in two strengths, $80 \mathrm{mcg} /$ actuation and $160 \mathrm{mcg} /$ actuation, administered twice-daily. The recommended starting dose for patients receiving as-needed inhaled bronchodilators alone is CIC $80 \mathrm{mcg}$ twice-daily with a maximum dose of $160 \mathrm{mcg}$ twice-daily. For patients receiving inhaled steroids, the starting dose is $80 \mathrm{mcg}$ twice-daily to a maximum dose of $320 \mathrm{mcg}$ twice-daily. For patients receiving oral corticosteroids, it is recommended that patients start at the maximal dose of $320 \mathrm{mcg}$ twicedaily with taper of oral prednisone no faster than $2.5 \mathrm{mg} /$ day on a weekly basis, starting at least 1 week after initiation of CIC therapy. ${ }^{3}$

\section{Pharmacologic features of ciclesonide Pharmacokinetics}

CIC is a nonhalogenated ICS that is available as a HFA-MDI in two strengths, $80 \mathrm{mcg} /$ actuation and $160 \mathrm{mcg} /$ actuation, and it is administered twice-daily. Like beclomethasone dipropionate, it is a prodrug that is converted to its active form desisobutyryl-ciclesonide (des-CIC) via esterases in the lung, maximizing its local effects. The parent compound $\mathrm{CIC}$ is inactive with a relatively low glucocorticoid-receptor affinity (RRA) of 12 . Des-CIC has a 100-fold greater relative-glucocorticoid-receptor-binding affinity than $\mathrm{CIC}$ $($ RRA $=1200)$. The potency of an ICS is assessed in terms of its relative receptor affinity versus dexamethasone, which is assigned a value of $100 .{ }^{4}$ An ICS with a higher RRA will induce a greater anti-inflammatory effect. In comparison with other available ICSs, des-CIC's RRA is between that of mometasone fuorate (MF) (which has a RRA of 2300), fluticasone propionate (FP) (RRA: 1800), and budesonide (BUD) (RRA: 935), and it is similar to beclomethasone monopropionate (17-BMP) (RRA: 1345). ${ }^{5}$ Increasing the potency of a glucocorticoid leads to higher topical efficacy but also may lead to more systemic activity and a higher incidence of systemic side effects, as the glucocorticoid receptor is expressed in almost all tissues and cells. ${ }^{5}$

ICSs are deposited in the upper airway and the lungs. Depending on the formulation and inhaler device, a large portion of the drug may be deposited in the oropharynx, swallowed, and then absorbed systemically where it can contribute to potential adverse effects. It is desirable for the oral bioavailability of ICSs to be low so that the drug has low systemic absorption from the gastrointestinal tract and for there to be extensive first-pass metabolism so that the amount of drug that is absorbed is rapidly cleared, minimizing systemic effects. CIC has been formulated as a solution HFA-MDI, with particles ranging 1.1-2.1 $\mu \mathrm{m}$, small enough to deposit in the small distal airways, which average $2 \mu \mathrm{m}$ in size. ${ }^{4}$ In two studies, one involving healthy subjects and a second study involving patients with mild asthma, technetium labeled CIC was shown to reach all regions of the lung with higher deposition in the peripheral regions than in the central region, and higher deposition in the whole lung than in the oropharynx. ${ }^{6,7}$ The inhaled bioavailability of desCIC is $52 \%$ compared with $17 \%$ for FP via DPI, $29 \%$ for FP via HFA-MDI, 68\% for FLU via HFA-MDI, 55\%-60\% for beclomethasone (BDP) via HFA-MDI, and $11 \%$ for $\mathrm{MF}^{5}$

CIC also exhibits low oropharyngeal deposition and low activation to des-CIC in the oropharynx. ${ }^{4}$ Any drug that reaches the systemic circulation binds to plasma proteins such as albumin and transcortin. Only the free, unbound drug is pharmacologically active and capable of suppressing endogenous cortisol. If the drug freely dissociates, this is not an issue. $\mathrm{CIC}$ has the highest degree of protein binding (99\%) followed by MF (98\%-99\%), 17-BMP (98.4\%) and FP $(90 \%) .^{5}$

Since there is low oropharyngeal deposition of CIC, low activation to des-CIC, and high protein binding, 
the potential for local and systemic side effects is low. Furthermore, any absorbed drug is subjected to nearly complete first-pass metabolism. This was demonstrated in a study where healthy subjects were given orally a single dose of $6.9 \mathrm{mg}$ of labeled CIC and intravenously $0.64 \mathrm{mg}$, and radioactivity was determined in blood, plasma, urine, and feces. Total radioactivity in the systemic circulation was low, and CIC was not detected in any serum sample. Serum concentrations of des-CIC were near or below the lower limit of quantification, giving a systemic bioavailability of $<1 \%$ for des-CIC. ${ }^{8}$ Elimination occurred mostly via the feces and was complete by 120 hours after both oral and IV administration. Following intravenous administration of $800 \mathrm{mcg}$ of CIC, the clearances of CIC and des-ciclesonide were high (approximately $152 \mathrm{~L} / \mathrm{h}$ and $228 \mathrm{~L} / \mathrm{h}$, respectively). ${ }^{3}$ ${ }^{14} \mathrm{C}$-labeled CIC was predominantly excreted in the feces after intravenous administration $(66 \%)$, indicating that excretion through bile is the major route of elimination. Approximately $20 \%$ or less of des-CIC was excreted in the urine. The mean half-life of CIC and des-CIC was 0.71 hours and 6-7 hours, respectively. $\mathrm{T}_{\max }$ of des-CIC occurs at 1.04 hours following inhalation of $\mathrm{CIC} .^{3}$

CIC has several favorable properties, including its prodrug structure, high-lipid affinity and glucocorticoid receptor-binding affinity of the active drug des-CIC, low oral deposition and bioavailability, extensive peripheral distribution in the lung, high protein-binding, and extensive first-pass metabolism. These properties may lead to a higher therapeutic efficacy and lower systemic exposure, thereby minimizing potential systemic effects.

\section{Pharmacodynamics}

CIC has been shown to have anti-inflammatory effects in vitro, with des-CIC conferring even greater anti-inflammatory activity. CIC and/or des-CIC were effective in inhibiting proinflammatory functions, including the stimulated expression of intracellular adhesion molecule-1, and stimulated release of inflammatory mediators such as granulocyte-macrophage colony-stimulating factor, monocyte chemoattractant protein (MCP)-1, interferongamma, interleukin (IL)-2, IL-4, IL-5, IL-8, and tumor necrosis factor (TNF)-a. CIC and des-CIC inhibited the induced proliferation of immune cells such as peripheral blood mononuclear cells, CD4 lymphocytes, and human airway smooth muscle cells..$^{9-11}$

In a small trial of patients with mild persistent asthma, once-daily CIC $320 \mathrm{mcg}$ significantly $(P<0.05$ versus placebo) inhibited levels of IL-12 and MCP-1 in sputum within 4 hours of administration. Inhibition of IL-12, MCP-1, IL1a, IL-6, IL-7, and IL-8 in sputum was observed within 4 hours of twice-daily administration of CIC $640 \mathrm{mcg}$ versus placebo $(P<0.01)$. After 1 week of treatment with twice-daily CIC $640 \mathrm{mcg}$, interferon (INF)-inducible protein 10 was significantly $(P<0.001)$ inhibited compared with placebo. ${ }^{12}$

Once-daily CIC $80 \mathrm{mcg}$ attenuated allergen-induced increases in the production of IL-4 and IL-5 in patients with mild atopic asthma. The drug also reduced chemokineinduced T-cell migration versus placebo prior to and 6 hours after allergen challenge. ${ }^{13}$

Several studies have shown that treatment with CIC reduced the percentage of eosinophils in induced sputum of patients with asthma. CIC (40 and $80 \mathrm{mcg} /$ day) attenuated the number of eosinophils in the sputum 8 hours but not 24 hours after allergen challenge. ${ }^{14}$ In another study, sputum eosinophilia was significantly attenuated with CIC 40 and $80 \mathrm{mcg} /$ day 24 hours after allergen challenge. ${ }^{15}$

Effect on eosinophil-cationic-protein release was not as consistent, with two studies ${ }^{16,17}$ showing reduction from pretreatment levels with CIC $400 \mathrm{mcg} /$ day; however, no effect was seen with CIC 100 and 1600 mcg in the one study. ${ }^{16}$ In another study, CIC $40 \mathrm{mcg}$ /day was found to attenuate allergen-induced reduction in IFN- $\gamma$-positive-CD4 T-cells 24 hours after provocation, although this effect was not seen with CIC $80 \mathrm{mcg} /$ day. ${ }^{14}$

CIC also reduced levels of exhaled nitric oxide (NO) in patients with mild to moderate asthma. In a randomized double-blind, placebo-controlled, randomized crossover, study of 17 patients, exhaled NO levels were measured after treatment with CIC 160 mcg once-daily for 4 weeks. Exhaled NO difference between CIC and placebo was 47 ppb (95\% confidence interval [CI]: $15-81 \mathrm{ppb}) .{ }^{18}$ A preliminary study suggested CIC produced a greater and more rapid reduction in exhaled NO than comparable doses of fluticasone. ${ }^{19}$

In summary, CIC has significant anti-inflammatory effects, which support its clinical efficacy in the studies that follow.

\section{Clinical efficacy and safety studies Ciclesonide versus placebo}

A 2008 Cochrane review evaluated randomized parallel or crossover studies comparing CIC at different doses with placebo. ${ }^{20}$ Eighteen trials, which included 6343 participants, of which 1692 were children, met the review entry criteria. 
At doses of $\leq 100-400 \mathrm{mcg} /$ day in mild to moderate asthma, CIC improved lung function, asthma symptoms, and rescue inhaler use, compared with placebo. Comparisons of CIC at different doses did not yield significant differences in lung function. The short duration of these trials precluded conclusions regarding the effectiveness of CIC in preventing asthma exacerbations.

Table 1 summarizes the key findings in a representative sample of trials comparing the efficacy and safety of CIC at different doses with placebo.

The US Food and Drug Administration recommended dosing was based on review of the above studies. The trial by Berger et al specifically demonstrated that CIC in a twicedaily dosing regimen was superior at improving pulmonary function and controlling disease symptoms than the CIC at twice the dose on a once-daily dosing regimen and was superior to placebo. ${ }^{25}$ This trial supported the presence of a dose frequency-dependent effect of the ICS on lung function and led to approval only for BID dosing in the USA.

Bateman et al investigated the effectiveness of CIC to reduce oral corticosteroid use in patients with severe, persistent asthma who were steroid dependent. ${ }^{26}$ Patients received CIC delivered via HFA-MDI at 320 mcg twice-daily, CIC delivered via HFA-MDI at $640 \mathrm{mcg}$ twice-daily, or placebo (all received at $8 \mathrm{am}$ and $8 \mathrm{pm}$ ). At study end, CIC $640 \mathrm{mcg} /$ day and CIC $1280 \mathrm{mcg} /$ day significantly reduced prednisone use whereas steroid use increased in the placebo group. Furthermore,
$30 \%$ of patients in the CIC groups were able to discontinue prednisone entirely and significantly fewer patients in the CIC groups required an increase in prednisone dose compared with placebo. These results suggest that CIC significantly reduces the need for oral corticosteroids in patients with severe, persistent asthma and maintains asthma control.

In summary, CIC has been demonstrated to be an effective ICS for patients with mild, moderate, and severe persistent asthma. Additionally, it can be beneficial in reducing oral corticosteroid requirements in OCS-dependent asthma patients.

\section{Comparisons with other inhaled corticosteroids}

A 2009 Cochrane review assessed the efficacy and adverse effects of CIC compared with those of other ICSs in the management of chronic asthma. ${ }^{27}$ Randomized parallel or crossover studies were reviewed. Studies comparing CIC with other steroids both at nominally equivalent dose or lower doses of CIC were included. Twenty-one trials involving 7243 participants (children and adults) were included. Equivalent daily doses of CIC and beclomethasone diproprionate (BDP) or BUD demonstrated similar results for peak expiratory flow rates. However, forced vital capacity (FVC) was higher with CIC, while forced expiratory volume $\left(\mathrm{FEV}_{1}\right)$ data were inconsistent. When $\mathrm{CIC}$ was compared with equivalent doses of $\mathrm{FP}, \mathrm{FEV}_{1}, \mathrm{FVC}$, and peak expiratory

Table I A representative sample of trials evaluating the efficacy of ciclesonide $(\mathrm{CIC})$ in the treatment of asthma in adults and adolescents

\begin{tabular}{|c|c|c|c|c|}
\hline Trial & $\begin{array}{l}\text { Study design } \\
\text { (n of patients) }\end{array}$ & Pulmonary function & Asthma symptom score & Rescue medication use \\
\hline Chapman et $\mathrm{al}^{21}$ & $\begin{array}{l}12 \text { wk, DB, R, PG, PC, } 329 \text { pts, } \\
\text { CIC I60, CIC 640, vs PL }\end{array}$ & $\begin{array}{l}\text { PEF and FEV, did not change } \\
\text { with either CIC dose, } \\
\text { decreased with PL }\end{array}$ & $\begin{array}{l}\text { Worsened with PL, stable } \\
\text { with either } \mathrm{ClC}^{\text {a }} \text { dose }\end{array}$ & $\begin{array}{l}\text { Increased in PL vs both CIC } \\
\text { groups }^{\mathrm{a}, \mathrm{b}}\end{array}$ \\
\hline Adachi et $\mathrm{a}^{22}$ & $\begin{array}{l}8 \text { wk, PC, DB, PG, CIC } 80 \text { (78), CIC } \\
160 \text { (7I), CIC } 320 \text { (83), vs PL (79) }\end{array}$ & $\begin{array}{l}\text { PEF did not change with any } \\
\text { CIC dose, decreased with } \text { L }^{\mathrm{a}}\end{array}$ & $\begin{array}{l}\text { Worsened with } \mathrm{PL} \text {, stable } \\
\text { with all } \mathrm{CIC} \text { doses }\end{array}$ & $\begin{array}{l}\text { Decreased in all } \mathrm{ClC} \text { groups } \\
\text { vs } \mathrm{PL}\end{array}$ \\
\hline Langdon et $\mathrm{al}^{23}$ & $\begin{array}{l}\text { I2 wk, R, PC, CIC } 80 \text { (I20), } 320 \\
\text { (I I5), vs PL (I25) }\end{array}$ & $\begin{array}{l}\text { PEF maintained in } \mathrm{CIC} \text { groups, } \\
\text { decreased in } \mathrm{PL}^{\mathrm{a}} \mathrm{FEV} \text {, increased } \\
\text { in } \mathrm{CIC} \text { groups, }{ }^{\mathrm{a}, \mathrm{c}} \text { slight decrease } \\
\text { in } \mathrm{PL}(P=0.54)\end{array}$ & $\begin{array}{l}\text { Worsened with PL, stable } \\
\text { with all CIC doses }\end{array}$ & $\begin{array}{l}\text { Stable in } \mathrm{CIC} \text { groups, } \\
\text { increased in PL }\end{array}$ \\
\hline Pearlman et al ${ }^{24}$ & $\begin{array}{l}\text { I } 2 \text { wk, MC, DB, R, PG, PC, CIC } 80 \\
\text { (257), CIC I60 (250), CIC } 320 \text { (255), } \\
\text { PL (249) }\end{array}$ & $\begin{array}{l}\mathrm{FEV}, \text { and } \mathrm{PEF} \text { improved in all } \\
\mathrm{CIC} \text { groups vs } \mathrm{PL}\end{array}$ & $\begin{array}{l}\text { Improved with all } \\
\mathrm{CIC} \text { groups vs PL }\end{array}$ & $\begin{array}{l}\text { Reduced in } \mathrm{CIC} \text { groups, } \\
\text { increased in } \mathrm{PL}\end{array}$ \\
\hline Berger et $\mathrm{a}^{25}$ & $\begin{array}{l}\text { I6 wk, MC, MN, DB, PG, PC, R, } \\
\mathrm{CIC} 80 \mathrm{BID}(\mathrm{I} 70), \mathrm{CIC} I 60 \text { QD } \\
\text { (I73), CIC } 80 \mathrm{BID} / \mathrm{CIC} \text { I60 QD } \\
\text { (I7I) PL (I77) }\end{array}$ & $\begin{array}{l}\text { FEV, improved in all CIC groups, } \\
\text { greatest improvement in CIC } \\
80 \text { BID. AM PEF improved } \\
\text { in all CIC groups }{ }^{\mathrm{a}} \text { vs PL }\end{array}$ & $\begin{array}{l}\text { Improved in all Rx groups, } \\
\mathrm{CIC} 80 \text { groups improved } \\
\text { vs PL }\end{array}$ & $\begin{array}{l}\text { Decreased in all treatment } \\
\text { groups, greatest reduction } \\
\text { in CIC groups }\end{array}$ \\
\hline
\end{tabular}

Abbreviations: DB, double blind; R, randomized; PG, parallel group; PC, placebo controlled; MC, multicenter; MN, multinational; AM, morning; PL, placebo; wk, week. Notes: ${ }^{a}$ No significant difference between $\mathrm{CIC}$ groups; ${ }^{b}$ o change from baseline; ${ }^{\mathrm{c}}$ versus baseline; only statistically significant differences are reported to $P<0.05$, unless otherwise noted; all reported doses are exactuator and in micrograms; all medication was delivered via hydrofluoroalkane metered dose inhaler; there were no significant adverse events noted in any of the studies. 
flow (PEF) did not differ significantly. Candidiasis was less frequent with CIC, although there were no significant differences in other side effects. When lower doses of CIC were compared with BDP or BUD, the difference in FEV did not reach significance. Other lung function outcomes did not demonstrate significant differences between treatments. Adverse events occurred with similar frequency between CIC and BDP/BUD. In three studies, CIC was compared with $\mathrm{FP}$ at half the nominal dose and $\mathrm{FEV}_{1}$ was not significantly different but was also not equivalent between the treatments (per protocol: $-0.05 \mathrm{~L}, 95 \% \mathrm{CI}-0.11-0.01$ ).
Table 2 reviews the key findings in a representative sample of trials comparing CIC to FP and BUD in adults and adolescents with mild, moderate, and severe persistent asthma. Of note, the majority of adverse events (AEs) were assessed as unrelated to study medication and were mild to moderate in intensity. No significant lab abnormalities were noted. In the Buhl et al ${ }^{28}$ study, three patients receiving FP developed oral AEs, including voice alteration or oral candidiasis. In the Boulet et $\mathrm{al}^{30}$ and Bateman et $\mathrm{al}^{31}$ studies, significantly more patients treated with FP developed local oral AEs. Hansel et a ${ }^{33}$ noted a significant decrease in urinary cortisol concentration in patients

Table 2 A representative sample of trials comparing the efficacy and safety of ciclesonide $(\mathrm{CIC})$ to other inhaled corticosteroids

\begin{tabular}{|c|c|c|c|c|}
\hline Trial & $\begin{array}{l}\text { Study design } \\
\text { (number of patients) }\end{array}$ & Pulmonary function & $\begin{array}{l}\text { Asthma } \\
\text { symptom score }\end{array}$ & $\begin{array}{l}\text { Rescue } \\
\text { medication use }\end{array}$ \\
\hline Buhl et $\mathrm{al}^{28}$ & $\begin{array}{l}\text { I } 2 \text { wk, MC, R, DB, DD, PG } \\
\text { study CIC I } 60 \text { qd }(266)^{\mathrm{b}} \text { vs } \\
\text { FP } 88 \text { BID }(263)^{\mathrm{b}}\end{array}$ & $\begin{array}{l}\text { PEF and FEV, improved } \\
\text { significantly in both groups }^{\mathrm{a}}\end{array}$ & $\begin{array}{l}\text { Improved in both } \\
\text { treatment groups }\end{array}$ & $\begin{array}{l}\text { Not different between } \\
\text { treatment groups }\end{array}$ \\
\hline Magnussen et $\mathrm{al}^{29}$ & $\begin{array}{l}\text { I } 2 \text { wk, DB, DD, PG, R, } \\
\text { CIC } 80 \text { qd }(278)^{\mathrm{b}}, \mathrm{CIC} \text { I } 60 \\
\text { qd }(27 \mathrm{I})^{\mathrm{b}} \text { or FP } 88 \text { BID }(259)^{\mathrm{b}}\end{array}$ & $\begin{array}{l}\text { FEV, improved significantly } \\
\text { in all } R x \text { groups }^{\mathrm{a}} \\
\text { Site measured PEF improved } \\
\text { significantly in all } \mathrm{Rx} \text { groups }\end{array}$ & $\begin{array}{l}\text { Improved in all } \\
\text { treatment groups }^{\mathrm{a}}\end{array}$ & $\begin{array}{l}\text { Decreased to similar } \\
\text { extent in all } \\
\text { treatment groups }^{\mathrm{a}}\end{array}$ \\
\hline Boulet et $\mathrm{al}^{30}$ & $\begin{array}{l}\text { I } 2 \text { wk, R, OL, PG, CIC } 320 \\
\text { qd }(234)^{b}, \text { FP } 200 \text { BID }(240)^{c}\end{array}$ & $\begin{array}{l}\text { FEV, improved significantly } \\
\text { in both } R x \text { groups }^{\mathrm{a}} \\
\text { AM PEF improved } \\
\text { significantly in CIC group }\end{array}$ & $\begin{array}{l}\text { Improved in both } \\
\text { groups }^{\mathrm{a}}\end{array}$ & $\begin{array}{l}\text { Decreased in both } \\
\text { treatment groups }\end{array}$ \\
\hline Bateman et $\mathrm{al}^{3 \mathrm{I}}$ & $\begin{array}{l}24 \text { wk, R, MC, OL, PG, } \\
\text { CIC } 320 \text { BID }(255)^{b} \\
\text { FP } 330 \text { BID }(273)^{b}\end{array}$ & $\begin{array}{l}\text { FEV, maintained in both } \\
\text { Rx groups } \\
\text { PEF improved significantly } \\
\text { in both } R x \text { groups }^{\mathrm{a}}\end{array}$ & $\begin{array}{l}\text { Improved in both } \\
\mathrm{Rx}_{\text {groups }}^{\mathrm{a}}\end{array}$ & $\begin{array}{l}\text { Decreased in both } \\
\text { Rx groups }\end{array}$ \\
\hline Niphadkar et al ${ }^{32}$ & $\begin{array}{l}\text { I2 wk, R, MC, PG, DB, DD, } \\
\text { of CIC with OL BUD BID, } \\
\text { CIC I60 QAM (I39) } \\
\text { CIC I60 QPM (I3I) or } \\
\text { BUD } 200 \text { BID }(133)^{b}\end{array}$ & $\begin{array}{l}\text { FEV, maintained in all } \\
R \times \text { groups }^{a} \\
\text { No significant differences } \\
\text { found among } R \times \text { groups } \\
\text { for PEF }\end{array}$ & $\begin{array}{l}\text { Maintained in all } \\
\text { Rx groups }{ }^{\mathrm{a}}\end{array}$ & $\begin{array}{l}\text { Maintained in all } \\
\text { Rx groups vs baseline }{ }^{a}\end{array}$ \\
\hline Hansel et $\mathrm{al}^{33}$ & $\begin{array}{l}\text { I } 2 \text { wk, MC, R, DB for CIC, } \\
\text { OL for BUD, of CIC } 80 \text { qd }(I 82)^{b} \text {, } \\
\text { CIC } 320 \text { qd }(195)^{b} \text { vs BUD } 200 \\
\text { BID }(I 77)^{f}\end{array}$ & $\begin{array}{l}\text { FEV, improved in all groups } \\
\text { at } 12 \text { wks. No significant difference } \\
\text { between CIC groups. } \\
\text { PEF improved in all groups }{ }^{a}\end{array}$ & $\begin{array}{l}\text { Improved in all } \\
\mathrm{R} \times \text { groups }\end{array}$ & $\begin{array}{l}\text { Decreased in } \\
\text { all groups }\end{array}$ \\
\hline Boulet et $\mathrm{al}^{34}$ & $\begin{array}{l}\text { I } 2 \text { wk MC, R, DB, DD, PG study, } \\
\text { CIC } 320 \text { qd }(179)^{\mathrm{b}} \text {, vs BUD } \\
320 \text { qd }(180)^{\mathrm{d}}\end{array}$ & $\begin{array}{l}\text { Change in FEV, was similar } \\
\text { in both } \mathrm{Rx} \text { groups. } \\
\text { Mean PEF did not change } \\
\text { in either Rx group }\end{array}$ & $\begin{array}{l}\text { No significant } \\
\text { difference in scores } \\
\text { between } \mathrm{Rx} \text { groups }\end{array}$ & $\begin{array}{l}\text { Decreased in } \\
\mathrm{CIC} \text { group }\end{array}$ \\
\hline Ukena et $\mathrm{a}^{35}$ & $\begin{array}{l}\text { I } 2 \text { wk DB, DD, R, PG study, } \\
\text { CIC } 320 \text { qd }(198)^{\mathrm{b}} \text { vs } \\
\text { BUD } 400 \text { qd }(201)^{d}\end{array}$ & $\begin{array}{l}\text { FEV, improved in both Rx groups, CIC } \\
\text { demonstrating superiority over BUD. } \\
\text { PEF improved in both Rx groups, } \\
\text { CIC showed greater } \\
\text { increase than BUD }\end{array}$ & $\begin{array}{l}\text { Improved in both } \\
\text { Rx groups }^{\mathrm{a}}\end{array}$ & $\begin{array}{l}\text { Decreased in both } \\
\text { Rx groups }\end{array}$ \\
\hline Vermeulen et $\mathrm{al}^{36}$ & $\begin{array}{l}\text { I } 2 \text { wk MC, R, DB, DD, PG, } \\
\text { CIC } 320 \text { qd }^{\mathrm{b}}(272) \text { vs } \\
\text { BUD } 800 \text { qd }(13 I)^{d}\end{array}$ & $\begin{array}{l}\text { FEV, increased in both } R \times \text { groups. }^{a} \\
A M \text { and PM PEF increased significantly } \\
\text { only in CIC group. }\end{array}$ & $\begin{array}{l}\text { Improved in both } \\
\mathrm{Rx}_{\text {groups }}^{\mathrm{a}}\end{array}$ & $\begin{array}{l}\text { Decreased in both } \\
\text { Rx groups }\end{array}$ \\
\hline
\end{tabular}

Notes: Only statistically significant differences are reported to $P<0.05$, unless otherwise noted; all reported doses are ex-actuator and in micrograms; ${ }^{\text {ano statistically }}$ significant difference noted between the treatment groups; 'belivered via HFA-M; 'delivered dry powder via inhaler (diskus); ddelivered via Turbohaler; ${ }^{f}$ delivered via dry powder inhaler; ${ }^{n}$ no significant change seen from baseline to study end.

Abbreviations: AM, morning; DB, double blind; DD, double dummy; R, randomized; PG, parallel group; PC, placebo controlled; MC, multicenter; OL, open label; CIC, Ciclesonide; FP, Fluticasone propionate; BUD, Budesonide; AE, adverse event; wk, week; Rx, treatment; qd, once-daily; BID, twice-daily; vs, versus; QAM, every morning; QPM, every evening; PEF, peak expiratory flow; $\mathrm{FEV}_{1}$, forced expired volume in one second. 
receiving BUD. Ukena et al ${ }^{35}$ noted four AEs (cough, headache, dyspnea, and voice alteration) potentially related to CIC.

\section{Effect of ciclesonide on HPA axis}

Dose-related adverse effects have been described for ICSs, especially in patients with moderate-to-severe asthma who may require higher doses to achieve asthma control. Systemic adverse effects that have been reported include osteoporosis, growth suppression, cataracts, glaucoma, and adrenal insufficiency, while local adverse effects include hoarseness, dysphonia, pharyngitis, and oral candidasis.

\section{HPA axis}

Lipworth evaluated the potential effects of CIC therapy on the dynamic cortisol response to sequential low- and high-dose cosyntropin stimulation in adults with mild-tomoderate persistent asthma. ${ }^{37}$ In a double-blind, placebocontrolled, 12-week study, 164 patients were randomized to placebo, $320 \mathrm{mcg}$ CIC once-daily, $320 \mathrm{mcg}$ CIC twice-daily (all CIC doses delivered via HFA-MDI), and $440 \mathrm{mcg}$ FP twice-daily delivered via CFC-MDI, all doses ex-actuator. Patients had normal HPA-axis function at screening and had not used systemic corticosteroids within 6 months of screening or inhaled or intranasal corticosteroids within 2 months of screening.

$\mathrm{CIC}$ at doses up to $640 \mathrm{mcg} /$ day does not affect sensitive markers of adrenal function. CIC did not produce any significant suppression of either basal cortisol levels or the response to cosyntropin stimulation, with results almost identical to the placebo group. In contrast, the FP group showed significant suppression of 24-hour-urinary-free cortisol levels and on high-dose cosyntropin stimulation compared to the placebo group. The differences between CIC groups and FP were statistically significant. Thus, CIC may result in less adrenal suppression than FP.

\section{Local effects}

Oral candidasis occurred in $22.0 \%$ of FP group compared with $2.4 \%$ in the combined CIC groups. Hoarseness occurred at a rate of $7.3 \%$ in the FP group and $2.4 \%$ in the combined CIC groups. ${ }^{37}$

\section{Systemic effects}

Other potential systemic effects of inhaled corticosteroids include decreased bone mineral density, cataract formation, glaucoma, and growth suppression.

Derom looked at markers of bone metabolism in a randomized, double-blind, double-dummy, placebo-controlled, five-period crossover study conducted at two centers. ${ }^{38}$
CIC 160, CIC 320 BID, FP 250 BID, FP 500 BID, or placebo were compared, which were administered in addition to a maintenance dose of CIC 160 qd. No significant differences were noted after any CIC treatment compared with placebo for any bone formation marker, which included N-terminal propeptide of type 1 procollagen (P1NP), alkaline phosphatase (AP), and serum osteocalcin. FP 1000 caused significant decreases in P1NP $(P=0.0126)$ and serum osteocalcin levels $(P=0.0054)$ compared with placebo. The clinical significance of these findings is not clear.

Chylack demonstrated that treatment with CIC $640 \mathrm{mcg} /$ day or beclomethasone dipropionate $640 \mathrm{mcg} / \mathrm{day}$ for 1 year had a minimal impact on lenticular opacity development and/or progression. ${ }^{39}$

A 52-week, multicenter, double-blind, randomized, placebo-controlled, parallel-group study was conducted to assess the effect of CIC on growth rate in 609 pediatric patients aged 5-8.5 years. Patients were randomized to CIC $40 \mathrm{mcg}, 160 \mathrm{mcg}$, or placebo once-daily. Growth was measured during baseline, treatment, and follow-up periods. There was no difference in efficacy measures, but conclusive results could not be drawn because compliance could not be assured. ${ }^{3}$

These studies suggest that CIC has minimal systemic adverse effects.

\section{Conclusion}

CIC is a nonhalogenated ICS, available as a HFA-MDI in two strengths, $80 \mathrm{mcg} /$ actuation and $160 \mathrm{mcg} /$ actuation, administered twice-daily. Several properties, including its prodrug structure, high lipid affinity, and glucocorticoid receptor-binding affinity of the active drug des-CIC, low oral deposition, low oral bioavailability, extensive peripheral distribution in the lung, high protein binding, and extensive first-pass metabolism, favor higher therapeutic efficacy and limited systemic exposure. CIC has significant anti-inflammatory effects that also contribute to its clinical efficacy. Studies have shown that CIC improves lung function, asthma symptoms, and rescue inhaler use, compared with placebo in patients with mild, moderate, and severe persistent asthma. CIC also significantly reduces the need for oral corticosteroids in patients with severe persistent asthma and maintains asthma control. CIC is at least as effective as FP, BUD, and beclomethasone propionate in maintaining pulmonary function, asthma control, and improving symptoms. Most significantly, CIC at doses up to $640 \mathrm{mcg} /$ day does not suppress either basal cortisol levels or the response to cosyntropin stimulation. CIC may 
cause less adrenal suppression than FP. Studies evaluating growth rate, lens opacity development, and markers of bone metabolism suggest that CIC's systemic effects are minimal. The unique contribution of CIC in the treatment of asthma lies in its excellent safety profile.

\section{Disclosure}

ES has no conflicts of interest to disclose in relation to this paper. JK discloses the following conflicts of interest:

- Current research: Forest Labs, Boerhingher-Ingelheim, Novartis, Genentech.

- Speaker's bureaus: Genentech, Novartis, Astra-Zenecca, Merck, Boehringher-Ingelhiem.

\section{References}

1. US Department of Health and Human Services; National Institutes of Health (NIH); National Heart, Lung, and Blood Institute. Expert Panel Report 3: Guidelines for the Diagnosis and Management of Asthma. NIH Publication No. 07-4051. Bethesda, MD: National Institutes of Health; 2007.

2. Global Initiative for Asthma (GINA). Global Strategy for Asthma Management and Prevention. GINA; 2010. Available from: http://www. ginasthma.org/pdf/GINA_Report_2010.pdf. Accessed July 11, 2011.

3. Sunovian Pharmaceuticals Inc. Alvesco ${ }^{\circledR}$ (ciclesonide) prescribing information. Marlborough, MA: Sunovian Pharmaceuticals Inc; 2008.

4. Nave R. Clinical pharmacokinetic and pharmacodynamic profile of inhaled ciclesonide. Clin Pharmacokinet. 2009;48(4):243-252.

5. Winkler J, Hochhaus G, Derendorf H. How the lung handles drugs: pharmacokinetics and pharmacodynamics of inhaled corticosteroids. Proc Am Thorac Soc. 2004;1(4):356-363.

6. Newman S, Salmon A, Nave R, Drollmann A. High lung deposition of $99 \mathrm{mTc}$-labeled ciclesonide administered via HFA-MDI to patients with asthma. Respir Med. 2006;100(3):375-384.

7. Leach CL, Bethke TD, Boudreau RJ, et al. Two-dimensional and threedimensional imaging show ciclesonide has high lung deposition and peripheral distribution: a nonrandomized study in healthy volunteers. J Aerosol Med. 2006;19(2):117-126.

8. Nave R, Bethke TD, van Marle SP, Zech K. Pharmacokinetics of [14C] ciclesonide after oral and intravenous administration to healthy subjects. Clin Pharmacokinet. 2004;43(7):479-486.

9. Boero S, Sabatini F, Silvestri M, et al. Modulation of human lung fibroblast functions by ciclesonide: evidence for its conversion into the active metabolite desisobutyryl-ciclesonide. Immunol Lett. 2007;112(1):39-46.

10. Silvestri M, Serpero L, Petecchia L, Sabatini F, Cerasoli F, Jr, Rossi GA. Cytokine-activated bronchial epithelial cell pro-inflammatory functions are effectively downregulated in vitro by ciclesonide. Pulm Pharmacol Ther. 2006;19(3):210-217.

11. Stoeck M, Riedel R, Hochhaus G, et al. In vitro and in vivo antiinflammatory activity of the new glucocorticoid ciclesonide. $J$ Pharmacol Exp Ther. 2004;309(1):249-258.

12. Erin EM, Zacharasiewicz AS, Nicholson GC, et al. Rapid effect of inhaled ciclesonide in asthma: a randomized, placebo-controlled study. Chest. 2008;134(4):740-745.

13. Heijink IH, Kauffman HF, Vellenga E, Veltman-Starkenburg CA, Postma DS, de Monchy JG. Effect of ciclesonide treatment on allergen-induced changes in $\mathrm{T}$ cell regulation in asthma. Int Arch Allergy Immunol. 2008;145(2):111-121.

14. Kawayama T, O'Byrne PM, Watson RM, et al. Effects of inhaled ciclesonide on circulating T-helper type 1/T-helper type 2 cells in atopic asthmatics after allergen challenge. Clin Exp Allergy. 2006;36(11): $1417-1424$.
15. Gauvreau GM, Boulet LP, Postma DS, et al. Effect of low-dose ciclesonide on allergen-induced responses in subjects with mild allergic asthma. J Allergy Clin Immunol. 2005;116(2):285-291.

16. Taylor DA, Jensen MW, Kanabar V, et al. A dose-dependent effect of the novel inhaled corticosteroid ciclesonide on airway responsiveness to adenosine-5'-monophosphate in asthmatic patients. Am J Respir Crit Care Med. 1999;160(1):237-243.

17. Kanniess F, Richter K, Bohme S, Jorres RA, Magnussen H. Effect of inhaled ciclesonide on airway responsiveness to inhaled AMP, the composition of induced sputum and exhaled nitric oxide in patients with mild asthma. Pulm Pharmacol Ther. 2001;14(2):141-147.

18. Wilson AM, Duong M, Pratt B, Dolovich M, O'Byrne PM. Antiinflammatory effects of once daily low dose inhaled ciclesonide in mild to moderate asthmatic patients. Allergy. 2006;61(5):537-542.

19. Zietkowski Z, Bodzenta-Lukaszyk A, Tomasiak MM, Szymanski W, Skiepko R. Effect of ciclesonide and fluticasone on exhaled nitric oxide in patients with mild allergic asthma. Respir Med. 2006;100(9):1651-1656.

20. Manning P, Gibson PG, Lasserson TJ. Ciclesonide versus placebo for chronic asthma in adults and children. Cochrane Database Syst Rev. 2008(2):CD006217.

21. Chapman KR, Patel P, D'Urzo AD, et al. Maintenance of asthma control by once-daily inhaled ciclesonide in adults with persistent asthma. Allergy. 2005;60(3):330-337.

22. Adachi M, Ishihara $\mathrm{K}$, Inoue $\mathrm{H}$, et al. Efficacy and safety of once-daily inhaled ciclesonide in adults with mild to moderate asthma: a doubleblind, placebo-controlled study. Respirology. 2007;12(4):566-572.

23. Langdon CG, Adler M, Mehra S, Alexander M, Drollmann A. Once-daily ciclesonide 80 or 320 microg for 12 weeks is safe and effective in patients with persistent asthma. Respir Med. 2005;99(10):1275-1285.

24. Pearlman DS, Berger WE, Kerwin E, Laforce C, Kundu S, Banerji D. Once-daily ciclesonide improves lung function and is well tolerated by patients with mild-to-moderate persistent asthma. J Allergy Clin Immunol. 2005;116(6):1206-1212.

25. Berger WE, Kerwin E, Bernstein DI, Pedinoff A, Bensch G, Karafilidis J. Efficacy and safety evaluation of ciclesonide in subjects with mild-tomoderate asthma not currently using inhaled corticosteroids. Allergy Asthma Proc. 2009;30(3):304-314.

26. Bateman E, Karpel J, Casale T, Wenzel S, Banerji D. Ciclesonide reduces the need for oral steroid use in adult patients with severe, persistent asthma. Chest. 2006;129(5):1176-1187.

27. Manning P, Gibson PG, Lasserson TJ. Ciclesonide versus other inhaled steroids for chronic asthma in children and adults. Cochrane Database Syst Rev. 2008(2):CD007031.

28. Buhl R, Vinkler I, Magyar P, et al. Comparable efficacy of ciclesonide once daily versus fluticasone propionate twice daily in asthma. Pulm Pharmacol Ther. 2006;19(6):404-412.

29. Magnussen H, Hofman J, Staneta P, Lawo JP, Hellwig M, Engelstatter R. Similar efficacy of ciclesonide once daily versus fluticasone propionate twice daily in patients with persistent asthma. $J$ Asthma. 2007;44(7):555-563.

30. Boulet LP, Bateman ED, Voves R, Muller T, Wolf S, Engelstatter R. A randomized study comparing ciclesonide and fluticasone propionate in patients with moderate persistent asthma. Respir Med. 2007;101(8):1677-1686.

31. Bateman ED, Linnhof AE, Homik L, Freudensprung U, Smau L, Engelstatter R. Comparison of twice-daily inhaled ciclesonide and fluticasone propionate in patients with moderate-to-severe persistent asthma. Pulm Pharmacol Ther. 2008;21(2):264-275.

32. Niphadkar P, Jagannath K, Joshi JM, et al. Comparison of the efficacy of ciclesonide 160 microg QD and budesonide 200 microg BID in adults with persistent asthma: a phase III, randomized, double-dummy, open-label study. Clin Ther. 2005;27(11):1752-1763.

33. Hansel TT, Benezet $\mathrm{O}, \mathrm{Kafe} \mathrm{H}$, et al. A multinational, 12-week, randomized study comparing the efficacy and tolerability of ciclesonide and budesonide in patients with asthma. Clin Ther. 2006;28(6): 906-920. 
34. Boulet LP, Drollmann A, Magyar P, et al. Comparative efficacy of once-daily ciclesonide and budesonide in the treatment of persistent asthma. Respir Med. 2006;100(5):785-794.

35. Ukena D, Biberger C, Steinijans V, et al. Ciclesonide is more effective than budesonide in the treatment of persistent asthma. Pulm Pharmacol Ther. 2007;20(5):562-570.

36. Vermeulen JH, Gyurkovits K, Rauer H, Engelstatter R. Randomized comparison of the efficacy and safety of ciclesonide and budesonide in adolescents with severe asthma. Respir Med. 2007;101(10): 2182-2191.
37. Lipworth BJ, Kaliner MA, LaForce CF, et al. Effect of ciclesonide and fluticasone on hypothalamic-pituitary-adrenal axis function in adults with mild-to-moderate persistent asthma. Ann Allergy Asthma Immunol. 2005;94(4):465-472.

38. Derom E, Louis R, Tiesler C, Engelstatter R, Kaufman JM, Joos GF. Effects of ciclesonide and fluticasone on cortisol secretion in patients with persistent asthma. Eur Respir J. 2009;33(6):1277-1286.

39. Chylack LT, Jr, Gross GN, Pedinoff A. A randomized, controlled trial to investigate the effect of ciclesonide and beclomethasone dipropionate on eye lens opacity. J Asthma. 2008;45(10):893-902.

\section{Publish your work in this journal}

Therapeutics and Clinical Risk Management is an international, peerreviewed journal of clinical therapeutics and risk management, focusing on concise rapid reporting of clinical studies in all therapeutic areas, outcomes, safety, and programs for the effective, safe, and sustained use of medicines. This journal is indexed on PubMed Central, CAS,
EMBase, Scopus and the Elsevier Bibliographic databases. The manuscript management system is completely online and includes a very quick and fair peer-review system, which is all easy to use. Visit http://www.dovepress.com/testimonials.php to read real quotes from published authors.

Submit your manuscript here: http://www.dovepress.com/therapeutics-and-clinical-risk-management-journal 